\title{
Observer Variability in Recording the Peripheral Pulses
}

\author{
T. W. MEADE, M. J. GARDNER, P. CANNON, AND P. C. RICHARDSON* \\ From the Medical Research Council's Social Medicine Research Unit, London School of Hygiene and
Tropical Medicine; and The London Hospital
}

Examination of the leg and foot pulses is indispensable in the assessment of the patient with suspected peripheral arterial disease, so it is important to know how much weight to attach to the findings. The topic of observer variability is of increasing interest in clinical medicine, while population studies can only be of use if methods are reproducible, that is provide "the same results on the same subject on two or more occasions, in the hands either of the same or of more than one observer, the subject of the test being in the same state of health or disease" (Fletcher and Oldham, 1964). A previous study of observer variability in recording pulses in the foot gave results from which the authors concluded that there was "very great observer error with respect to the detection of ankle pulses", and that "the inability to detect an ankle pulse by one observer is quite without significance" (Ludbrook, Clarke, and McKenzie, 1962). These are disturbing suggestions for the clinician and the epidemiologist, particularly in view of the considerable attention currently being paid to the detection of early peripheral arteriosclerosis (Widmer, Greensher, and Kannel, 1964; Cooper, Hill, and Edwards, 1967; Lancet, 1967).

Preparing for population studies of peripheral arterial disease, it was obviously necessary first to carry out a similar study to that of Ludbrook et al. (1962), in order to reassess the value of palpation of the pulses.

Apart from an unexplained random element, intra-observer variability may be due to real biological changes of the factor considered, e.g. seasonal changes in blood cholesterol or changes in blood pressure with emotion. In addition, errors generated by the observer and/or his instrument may result in different recordings on separate occasions for a factor that has not altered, e.g. the observer

Received November 27, 1967.

* Present address: Mile End Hospital, London E.1. may find a lesion present on a chest $x$-ray film the first time he sees it but not on the same film at a later date. Sources of inter-observer variability are similar, though the effects of biological changes can be minimized if observers examine the subject at the same time and under similar conditions. But if one observer is systematically different from his colleagues, and regularly records higher or lower blood pressure readings for example, or finds more or fewer lesions on chest $x$-rays, an additional source of variability is introduced.

Compared with ischaemic heart disease and cerebrovascular disease, our knowledge of peripheral arterial disease is scanty, both as regards prevalence and aetiology. Epidemiological studies of peripheral arterial disease can contribute an overall picture of its manifestations (Morris, 1967). Methodological difficulties will have to be resolved first, and the present study deals with observer variability in recording peripheral pulses. It also provides some evidence on the interrelationships of degenerative arterial disease at the three main sites.

\section{SUBJECTS AND METHOD}

Three observers of comparable clinical experience in the present topic each examined the femoral, posterior tibial, and dorsalis pedis pulses of a sample of 84 male hospital in-patients. The subjects were all admitted to one medical ward of The London Hospital over a period of about 4 months. Six were examined at weekly sessions, each of which started with a patient randomly selected by bed-number, and, omitting the seriously ill, proceeded according to next ascending bed-number until 6 were included. To provide cases for study of intra-observer variability, one patient at any session who had been included in the study on a previous occasion was re-examined if selected a second time by this procedure: 12 of the 84 patients were so re-examined.

The patients in each session were seen in 2 groups of 3. Each observer went to one in the first group, and spent a maximum of 5 minutes examining him behind drawn 661 
two patients, and so on, until all 3 observers had seen all 3 patients in the first group. The session was completed by repeating this procedure with the 3 patients in the second group. Each observer recorded 6 pulses per patient ( 2 femoral, 2 posterior tibial, and 2 dorsalis pedis) as "present" or "absent". "Doubtful" or "?" recordings were not permitted. There was no discussion between observers, and no results were compared till the whole study had ended. None of the patients was questioned by any of the observers, and no notes, temperature charts, or other clinical documents were consulted. The order in which the observers followed each other to a particular patient was randomized so as to allow for possible patient-observer interactions that might vary according to observer order. This "observer following order" was so arranged that by the end of the study each observer had seen the same number of patients first, second, or third, and had followed each of the other two observers equally often. Sixteen sessions were held in all.

The clinical diagnoses of all the patients, as stated on their discharge summary sheets, were collected at the conclusion of the study. From these, independently made by doctors not involved in the study, patients were classified by another doctor also unconnected with the investigation into the following groups: (i) peripheral arterial disease present; (ii) cerebrovascular disease present; (iii) ischaemic heart disease present; (iv) no mention of any kind of arterial disease. Of the 84 men, 34 had clinical arterial disease so recorded at one or more sites.

\section{RESULTS}

As 12 of the patients were examined twice, 96 "patient-examinations" were made in all: The average length of time between the two examinations of these 12 patients was three weeks (range 1-9 weeks), and it is therefore unlikely that recall of the first examination by any observer influenced his findings at the second. For this reason, the 96 "patient-examinations" are treated independently in the part of the results dealing with inter-observer variability. The results on the 12 patients seen twice are used later to assess intra-observer variability; here, of course, the two sets of findings by each observer are directly related to the particular patient involved in each examination and reexamination.

Agreement by Observers on Individual Pulses. This is summarized in Table I. For any particular pulse, there are 4 possible ways in which 3 observers may agree or disagree on its presence or absence. They may all agree that a particular pulse is present, or that it is absent. They disagree if 2 find it present and 1 finds it absent, or if 2 find it absent and 1 finds it present. From Table $I$ it can be seen that agreement on the femoral pulses was virtually complete and that they were nearly all recorded as "present"; we do not consider them further. However, agreement on the posterior tibial and dorsalis pedis pulses is also of a high order, and in fact there was complete agreement on 74 per cent. Table I also shows that there were far more agreements (and, therefore, fewer disagreements) than might be expected by chance. The method therefore is satisfactorily repeatable or "reproducible".

Improvement with Practice. Ludbrook et al. (1962) concluded that observer error in detection of pulses "seems independent of acquired skill". The Figure shows the cumulative proportion of pulses in the feet recorded as absent by each of the three observers in relation to the number of sessions completed. It is clear that, as the sessions progressed, the three observers were tending towards similar cumulative proportions. There was also some early, if unsustained, movement towards complete agreement on presence or absence of particular

TABLE I

AGREEMENT ON PULSES: DISTRIBUTION OF AGREEMENT OR DISAGREEMENT OF 3 OBSERVERS EXAMINING FEMORAL, POSTERIOR TIBIAL, AND DORSALIS PEDIS PULSES IN 96 MALE PATIENTS

\begin{tabular}{|c|c|c|c|c|c|}
\hline \multirow[b]{2}{*}{ Pulses } & \multirow{2}{*}{$\begin{array}{c}\text { Agreement } \\
\text { Pulses recorded } \\
\text { present by } \\
3 \text { observers }\end{array}$} & \multicolumn{2}{|c|}{ Disagreement } & \multirow{2}{*}{$\begin{array}{c}\text { Agreement } \\
\begin{array}{l}\text { Pulses recorded } \\
\text { absent by } \\
3 \text { observers }\end{array}\end{array}$} & \multirow{2}{*}{$\begin{array}{l}\text { Agreement } \\
\text { as per cent of } \\
\text { totail number of } \\
\text { pulses recorded }\end{array}$} \\
\hline & & $\begin{array}{l}\text { Pulses recorded } \\
\text { present by } \\
2 \text { observers and } \\
\text { absent by } 1\end{array}$ & $\begin{array}{c}\text { Pulses recorded } \\
\text { absent by } \\
2 \text { observers and } \\
\text { present by } 1\end{array}$ & & \\
\hline $\begin{array}{l}\text { Right and left femoral (192 pulses) } \\
\text { Right and left posterior tibial (192 pulses) } \\
\text { Right and left dorsalis pedis (192 pulses) } \\
\text { Total of } 2 \text { posterior tibial and } 2 \text { dorsalis } \\
\text { pedis (384 pulses) }\end{array}$ & $\begin{array}{l}187 \\
126 \\
105 \\
231 \\
\left(153^{\star}\right)\end{array}$ & $\begin{array}{c}4 \\
27 \\
29 \\
56 \\
\left(165^{\star}\right)\end{array}$ & $\begin{array}{c}1 \\
13 \\
30 \\
43 \\
\left(59^{\star}\right)\end{array}$ & $\begin{array}{l}0 \\
26 \\
28 \\
54 \\
\left(7^{\star}\right)\end{array}$ & $\begin{array}{c}97 \\
79 \\
69 \\
74 \\
\left(42^{\star}\right)\end{array}$ \\
\hline
\end{tabular}

* On the assumption that each observer is guessing at random, with a fixed probability of assessing each pulse as present, these figures are expected numbers for comparison with those actually observed. (The probability, $p=0 \cdot 736$, is estimated by the over-all proportion of pulses recorded as present.)

Mean age of patients: 55 years (range, 22-86 years). 


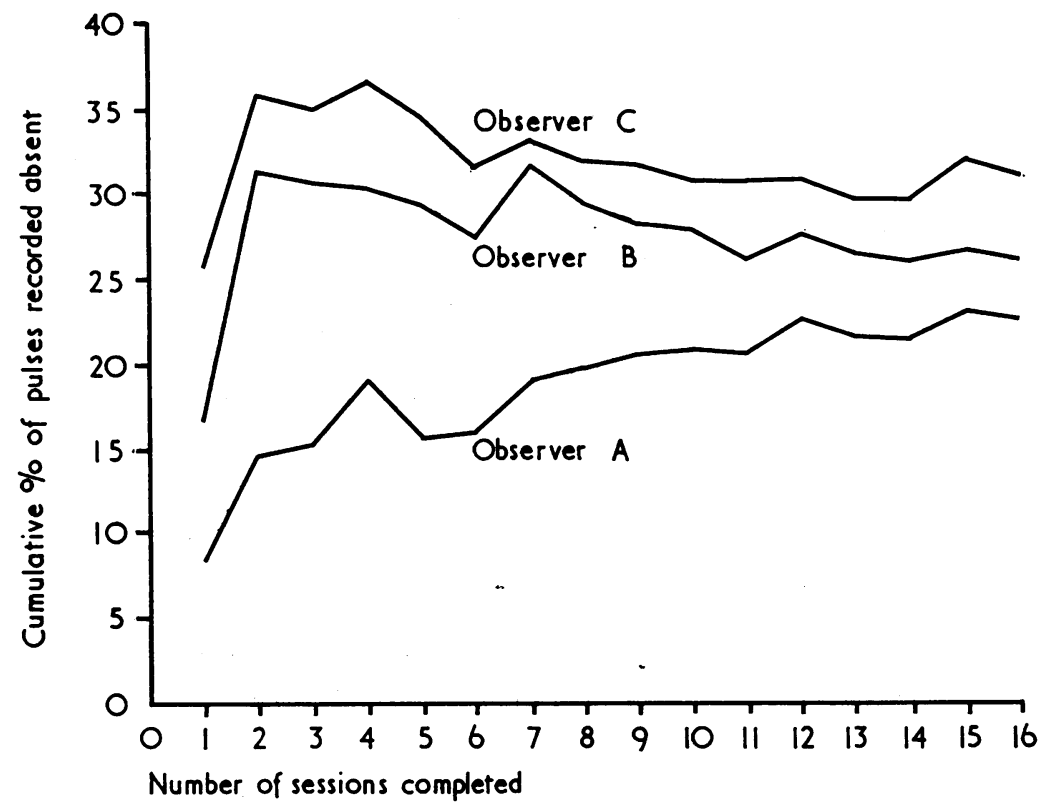

FIG.-Cumulative percentage of pulses (posterior tibial and dorsalis pedis) recorded absent by each observer according to number of sessions completed.

pulses by all three observers. Thus, there were 62 complete agreements (out of a possible total of 96) in the first group of 4 sessions, 75 in the second, and 74 each in the third and fourth groups. In contrast, therefore, to the study of Ludbrook et al. (1962), these findings suggest that "acquired skill" or practice may favourably influence the amount of observer variability or "error".

Intra-observer Variability. Table II shows for the 12 patients examined twice how many pulses in the feet each observer found present at one examination and absent on the other, i.e. how often he disagreed with himself on an individual pulse. The proportion of pulses on which such disagreement occurred ranged from 13 to 27 per cent, but some of this apparent intra-observer variability is undoubtedly biological, and not really due to error. Thus, one patient was in a hypothermic condition when first seen, and the pulses in his feet were nearly all agreed to be absent; after treatment, and at reexamination, they were nearly all agreed present.

\section{Findings According to Disease}

The design of the study offered an opportunity to look at the interrelationships of degenerative arterial disease at different sites. None of the observers had seen any of the patients before the study, and, except in a few cases where obvious physical signs or therapeutic apparatus gave a clue, they did not know the diagnoses until the study was over. It was, therefore, reasonable to see whether patients with ischaemic heart disease and cerebrovascular disease had fewer pulses in their feet than those without any known arterial disease, as might be expected.

For each patient, an average number of pulses present in the feet was obtained by adding together the number of these pulses recorded as present by each individual observer (regardless of his agreement with the other 2), and dividing this total by 3 . The 5 patients with a clinical diagnosis of peripheral arterial disease had a mean of 0.3 pulses in their feet (out of a maximum of 4, i.e., 2 posterior tibial and 2 dorsalis pedis). The 6 patients with cerebrovascu-

TABLE II

INTRA-OBSERVER VARIABILITY IN RECORDING POSTERIOR TIBIAL AND DORSALIS PEDIS PULSES IN 12 PATIENTS

\begin{tabular}{c|c}
\hline Observer & $\begin{array}{c}\text { No. of individual pulses found present on } \\
\text { one examination and absent on another } \\
\text { (48 pulses) }\end{array}$ \\
\hline A & $8 / 48(17 \%)$ \\
C & $6 / 48(13 \%)$ \\
$13 / 48(27 \%)$
\end{tabular}

$x^{2}=3.56 ; \mathrm{DF}=2 ; \mathrm{p}>0.1$ (NS). 
lar disease had a mean of $2 \cdot 2$, and the 29 patients with ischaemic heart disease had a mean of 2.4 . The 59 with no clinical evidence of any of the main forms of arterial disease had 3.4 pulses on average. (The total of 99 patients given here is due to the 12 who were examined twice, one patient with arterial disease at two sites, and one with disease at all three sites.)

\section{Discussion}

Agreement between observers on the palpation of pulses in the feet reached satisfactory levels. It appears that such variability as there is decreases with practice.

A major difficulty has been the lack of an independent assessment of whether a particular pulse really is present or not, i.e. whether the observations made are valid. It is obviously encouraging that patients with clinical peripheral arterial disease were found to have substantially fewer pulses than those without, but because all three observers agree a pulse is present it does not follow that they are correct; similarly, one observer is not necessarily wrong about a pulse if he disagrees with the other two about it. Validation implies independent assessment by a better method. Such a check is not available at present for the examination of peripheral pulses. The arteriographic demonstration of a vessel in the foot does not necessarily mean that a corresponding pulse can be felt, though a correlation between these two methods would be expected. Moreover, there are obvious practical as well as ethical drawbacks to this and other instrumental methods of validation (Lancet, 1967).

The main implications of the different numbers of pedal pulses in the clinical disease groups is that patients with arterial disease at one site are likely to have signs of similar disease elsewhere. Obvious though this proposition seems, clinical evidence for it is slender. But pathological studies (Morris, 1951; Mitchell and Schwartz, 1965) have shown clearly that arterial disease must increasingly be thought of and investigated as a whole, and not only by particular site.

We conclude that examination of the peripheral pulses is an adequately reproducible method, and in consequence larger epidemiological studies of peripheral arterial disease are now under way. Of equal importance, however, and contrary to the suggestion of Ludbrook et al. (1962), it is useful and justifiable in the day-to-day clinical situation. Pulse palpation is a common, routine examination, and much may depend on it. The results of the present study are therefore reassuring. Furthermore, re-reading the report of Ludbrook et al. (1962), it seems possible that its disappointing find- ings were due to the methods of analysis used, rather than to intrinsic disagreements between the observers.

We have been able to express our findings in the same manner as Ludbrook et al., i.e. to estimate the probability that if one observer cannot detect a pulse, the other two observers will agree with him. Table III gives these probabilities from our study, and from Ludbrook et al. (The latter authors give figures for separate age-groups; we have amalgamated these for easy comparison.)

TABLE III

PROBABILITY THAT IF ONE OBSERVER CANNOT DETECT A PULSE TWO OTHER OBSERVERS WILI AGREE WITH HIM

\begin{tabular}{l|l|c}
\hline & Posterior tibial & Dorsalis pedis \\
\hline $\begin{array}{ll}\text { Present study } \\
\text { Ludbrook et al. (1962) }\end{array}$ & $\begin{array}{l}0.59(0.05) \\
0.57(0.0002)\end{array}$ & $\begin{array}{l}0.49(0.09) \\
0.52(0.01)\end{array}$ \\
\hline
\end{tabular}

Expected values are shown in brackets.

Making the same assumptions as in the footnote to Table I we have calculated expected values, $(1-p)^{2}$, for these probabilities, and these are also shown in Table III. It is clear that the observed values are very much greater than would have occurred had the observers been guessing. In fact, the probability of getting a chance value as high, for example, as 0.49 , our figure for the dorsalis pedis pulse, is less than one in a million $\left(1 \times 10^{-6}\right)$. A refinement is to calculate the expected values in Table III, for our study, by using different estimates for $\mathbf{p}$ for men with and without arterial disease. We have done this; the observed values remain significantly higher than the expected values. From the published data of Ludbrook et al. it has not been possible to express their findings in our terms of percentage agreements, as in Table $I$. However, it can be deduced that their results would have led to over-all agreements of not less than 94 per cent for the posterior tibial and not less than 85 per cent for the dorsalis pedis pulses. Thus, we feel that these authors achieved agreement similar to or better than our own (though they omitted all patients with any kind of arterial disease from their study), and that while some observer variability undoubtedly occurs, they need not have questioned so fundamentally the value of examining the peripheral pulses.

\section{SUMMARY}

Three observers palpated the femoral, posterior tibial, and dorsalis pedis pulses of a sample of 84 male patients. Agreement between observers on 
the presence or absence of individual pulses was excellent for the femorals and satisfactory for those in the foot. Agreement increases with practice. A limited assessment suggests that intra-observer variability is also at an acceptable level. Examination of pedal pulses is an adequately reproducible method for assessment of the peripheral circulation in clinical and epidemiological work. As well as those with peripheral arterial disease, men with ischaemic heart and cerebrovascular disease had fewer pulses in the feet than other men.

We are very grateful to Professor C. Wilson, Professor J. M. Ledingham, and Dr. M. A. Floyer for allowing us to examine patients under their care. We wish to thank them and Professor J. N. Morris, Director of the M.R.C. Social Medicine Research Unit, Dr. J. A. Heady, and Dr. M. R. Alderson for much helpful advice in planning the study, and in analysing the results.

\section{REFERENCES}

Cooper, D., Hill, L. T., and Edwards, E. A. (1967). Detection of early arteriosclerosis by external pulse recording. f. Amer. med. Ass., 199, 449.

Fletcher, C. M., and Oldham, P. D. (1964). Diagnosis in group research. In Medical Surveys and Clinical Trials, 2nd ed., p. 30. Ed. by L. J. Witts. Oxford University Press, London.

Lancet (1967). Detection of early arteriosclerosis. 1, 1315.

Ludbrook, J., Clarke, A. M., and McKenzie, J. K. (1962). Significance of absent ankle pulse. Brit. med. $\mathcal{F} ., 1$, 1724.

Mitchell, J. R. A., and Schwartz, C. J. (1965). Arterial Disease. Blackwell Scientific Publications, Oxford.

Morris, J. N. (1951). Recent history of coronary disease. Lancet, 1,1 and 69.

- (1967). Uses of Epidemiology, 2nd ed. Livingstone, Edinburgh.

Widmer, L. K., Greensher, A., and Kannel, W. B. (1964). Occlusion of peripheral arteries. A study of 6,400 working subjects. Circulation, $\mathbf{3 0}, 836$. 